\section{THU0652 COMPARATIVE COST PER RESPONSE FOR FOUR CLINICAL OUTCOMES OF TOCILIZUMAB MONOTHERAPY VERSUS ADALIMUMAB MONOTHERAPY IN A HEAD-TO-HEAD RANDOMISED DOUBLE-BLIND SUPERIORITY TRIAL (ADACTA) IN PATIENTS WITH RHEUMATOID ARTHRITIS}

J. Best, J. Pei. Genentech, Inc., South San Francisco, USA

Background: The cost-effectiveness of different biologic therapies is an important component in guiding treatment decisions for patients with rheumatoid arthritis (RA).

Objectives: To compare drug and adverse event costs and cost per successful clinical response with tocilizumab (TCZ) monotherapy vs adalimumab (ADA) monotherapy in patients with RA.

Methods: Patients in the ADACTA trial ${ }^{1}$ were randomised to either TCZ $8 \mathrm{mg} / \mathrm{kg}$ intravenously every 4 weeks or ADA $40 \mathrm{mg}$ subcutaneously every 2 weeks as monotherapy for 24 weeks. Drug costs of $\$ 397.71 / 80 \mathrm{mg}$ vial for TCZ (plus $\$ 136$ administration cost per infusion) and $\$ 2220.62 / 40 \mathrm{mg}$ for ADA were based on Wholesale Acquisition Costs (WAC) drug prices (July 2017). Outcomes included patient-level drug costs and cost of hospitalisation due to adverse events, and cost per response. Cost per response was calculated by dividing the mean drug plus administration cost by the proportion of patients achieving Disease Activity Score-28 joints (DAS28) $<2.6$ (remission) or American College of Rheumatology response criteria $20 \% / 50 \% / 70 \%$ (ACR20/ACR50/ACR70). The proportions of patients achieving DAS28 $<2.6$, ACR 20, ACR50 and ACR70 were $39.9 \%, 65.0 \%$, $47.2 \%$ and $32.5 \%$ for $T C Z$, respectively, and $10.5 \%, 49.4 \%, 27.8 \%$ and $17.9 \%$ for ADA, respectively; $p<0.0001, p=0.0038, p=0.0002, p=0.0023$ for TCZ vs ADA, respectively. Hospitalisation costs were calculated using the daily hospital cost of $\$ 2433$ (2017) and number of hospital days.

Results: Among the 163 patients treated with TCZ and 162 with ADA, mean total drug and administration costs per patient over 24 weeks were $\$ 16,674.74$ and $\$ 23,357.63$, respectively. Mean drug and administration costs were lower per each clinical response achieved with TCZ compared with ADA (DAS28 <2.6: $\$ 41791$ vs $\$ 222,454$; ACR20: $\$ 25653$ vs $\$ 47,283$; ACR50: $\$ 35328$ vs $\$ 84,020$; ACR70: $\$ 51307$ vs $\$ 130,490)$. The total hospital days/costs were $32 / \$ 77856$ for TCZ and 43/\$1 04619 for ADA.

Conclusions: In this comprehensive comparative assessment, the cost to achieve all four clinical responses was lower for patients receiving TCZ than for ADA.

\section{REFERENCE:}

[1] Gabay C, et al. Lancet 2013;381:1541-1550.

Acknowledgements: This study was funded by Genentech, Inc

Disclosure of Interest: J. Best Shareholder of: Genentech, Inc., Employee of: Genentech, Inc., J. Pei Shareholder of: Genentech, Inc., Employee of: Genentech, Inc.

DOI: 10.1136/annrheumdis-2018-eular.2009

\section{THU0653 CHANGES IN RHEUMATOLOGY PROVISION AND PRACTICE IN A PUBLICLY-FUNDED SINGLE PAYER HEALTHCARE SYSTEM}

J. Widdifield ${ }^{1}$, S. Bernatsky ${ }^{2}$, V. Ahluwalia ${ }^{3}$, C. Barber ${ }^{4}$, L. Eder ${ }^{5}$, C. Hofstetter ${ }^{6}$,

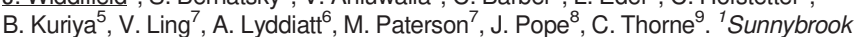
Research Institute, Toronto; ${ }^{2}$ McGill University, Montreal; ${ }^{3}$ William Osler Health System, Brampton; ${ }^{4}$ University of Calgary, Calgary; ${ }^{5}$ University of Toronto; ${ }^{6}$ Ontario Rheumatology Association; ' Institute for Clinical Evaluative Sciences, Toronto; ${ }^{8}$ Western University, London; ${ }^{9}$ Southlake Regional Health Centre, Newmarket, Canada

Background: The global shortage of rheumatologists is an increasing concern. Statistics from physician surveys have projected changes in the workforce composition (ageing, feminization, and generational trends), which have implications for the workforce clinical activity. In order to adequately document the issues and potential solutions, more detailed information is needed regarding clinical activity, demographic changes and the implications of these, in a population-based sample.

Objectives: To describe changes in the number, demographics and clinical activity of Ontario rheumatologists over the past decade.

Methods: We analysed administrative health data from 2000 to 2013 in Ontario, Canada, where all 13 million residents are covered by a publicly funded healthcare system. Rheumatologists, and their characteristics, were identified using a validated physician registry. We used fee-for-service billing claims to quantify clinical activity levels expressed as full-time equivalents (FTE). Physicians below the 40th percentile of total billings were classified as providing less clinical activity
( $<1$ FTE i.e. professor/scientist); 40-60th percentile were classified as 1 FTE; and $>60$ th percentile as $>1 \mathrm{FTE}$ (i.e. high volume community practice).

Results: In 2000, there were 146 rheumatologists in Ontario (88 of whom worked $\geq 1$ FTEs); this increased to 187 rheumatologists (114 $>1$ FTEs) in 2013 Despite the increase, due to an increase in the Ontario population over this time, the proportion of Ontarians seen by a rheumatologist annually remained constant $(2.7 \%)$ as was the overall provincial per capita supply (1.2 rheumatologists per 75000 population, $0.7 \mathrm{FTEs} / 75,000)$. In $2000,34 \%$ of rheumatologists were female compared to $48 \%$ in 2013. During this time, the proportion of rheumatologists aged $>60+$ years increased $(16 \%$ to $26 \%$ ). The annual median (IQR) number of days of clinical service decreased from $220^{178-243}$ days in 2000 to $176^{138-}$ ${ }^{213}$ days in 2013. The percentage of rheumatologists with patient encounters on at least 209 days/year (an alternative FTE benchmark) showed a downward trend from $46 \%$ in 2000 to $22 \%$ in 2013. Male rheumatologists had more patient encounters each year, and a higher proportion of male rheumatologists worked as $\geq 1$ FTE. Average practice sizes declined over time (figure 1A), as did the median number of patient encounters per rheumatologist per year (figure 1B).

A

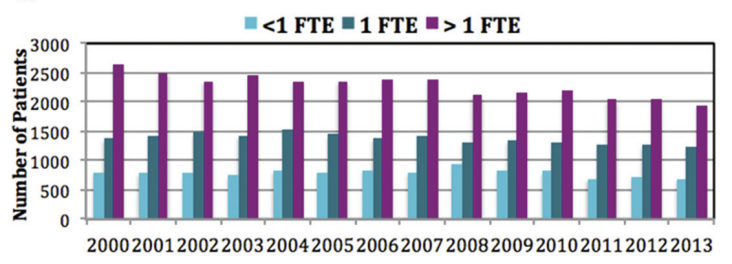

B

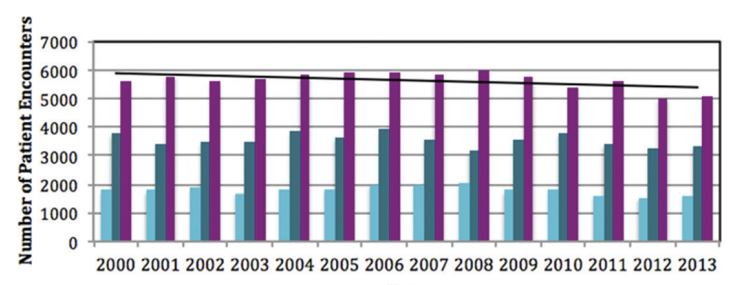

Year

Abstract THU0653 - Figure 1. A) Average Rheumatology Practice/Panel Size (Number of Unique Patients per Rheumatologists) According to FTE Classification; B) Average Number of Patient Enounters per Rheumatologist According to FTE Classification

Conclusions: Although there has been an increase in the number of rheumatologists, the per capita supply and access to rheumatologists have remained unchanged. We observed changing workforce demographics and declining clinical activity over time. Factors affecting clinical activity (including an ageing and greater feminization of the workforce, clinic saturation, increasing care complexity, models of care, greater demands for continuing medical education and research activity) warrants further study.

Disclosure of Interest: None declared

DOI: 10.1136/annrheumdis-2018-eular.3372

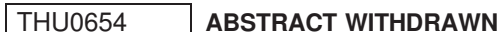

\section{THU0655 PATIENTS' EVALUATION OF DUTCH HEALTH CARE IN SYSTEMIC SCLEROSIS: UNMET NEEDS AND PREFERENCES}

J. Spierings ${ }^{1}$, C.H. van den Ende ${ }^{2,3}$, M.R. Schriemer ${ }^{4}$, J.K. de Vries-Bouwstra ${ }^{5}$, M. C. Vonk ${ }^{3} .{ }^{1}$ Department of Rheumatology and Clinical Immunology, University Medical Centre Utrecht, Utrecht, ${ }^{2}$ Department of Rheumatology, st Maartenskliniek; ${ }^{3}$ Department of Rheumatology, Radboud University Medical Centre, Nijmegen; ${ }^{4}$ Schriemer Peilt, Rotterdam; ${ }^{5}$ Department of Rheumatology, Leiden University Medical Centre, Leiden, Netherlands

Background: Systemic sclerosis (SSc) is a chronic, heterogeneous autoimmune disease with a large impact on quality of life. To optimise health care, more insigh is needed in patients' experiences of the currently provided care.

Objectives: To identify unmet needs and preferences from a patient point of view regarding health care in the Netherlands

Methods: 2093 patients with SSc, from both regional $(n=7)$ and university hospitals $(n=6)$ in the Netherlands, were invited through their rheumatologist for an online, anonymous questionnaire comprising multiple choice, multiple response 
and open questions about health care needs, quality of care (CQ index), and additional sociodemographic characteristics. Questions were based on results from a literature study and three semi-structured multicenter focusgroup interviews with 23 patients. Eight themes were identified (table 1).

Results: 493 patients, median age was 60 years and $73 \%$ were women, completed the questionnaire at the 10th of January 2018. Inclusion is still ongoing. Patients had been diagnosed for a median period of four years, $38 \%$ and $23 \%$ reported having been diagnosed with limited or diffuse cutaneous SSc, respectively. Interestingly, 39\% did not know the subtype. 50\% received care in a centre of expertise and $32 \%$ in $\geq$ two centres. $32 \%$ had to travel $>$ one hour for each visit. Themes containing the most important unmet needs were ${ }^{1}$ multidisciplinary collaboration; ${ }^{2}$ education of caregivers $;{ }^{3}$ patient information $;{ }^{4}$ the role of the patient and $;{ }^{5}$ non-pharmacological care. Multidisciplinary collaboration was rated 68 out of 100 and information exchange among physicians 66 out of 100 . The lack of knowledge about the disease among health professionals (40\%) and difficulty finding experts in SSc (25\%) were most reported hurdles. $10 \%$ of patients did not receive any information from the rheumatologist at time of diagnosis, but when provided $97 \%$ thought this information was clear. Although most of the patients were involved in treatment decisions (83\%), $12 \%$ did not receive the care they needed in their opinion. $60 \%$ was referred to a specialised nurse for non-pharmacological support. During hospital visits, more focus was preferred on fatigue $(45 \%, n=227)$, Raynaud's phenomenon $(31 \%, n=155)$, physical disabilities $(29 \%$, $n=147)$, impaired hand function $(26 \%, n=129)$ and coping with the unpredictable course of the disease $(25 \%, \mathrm{n}=124)$. Highest priority was given to improved knowledge among general practitioners (67\%), multidisciplinary collaboration $(43 \%)$ and information exchange among health care providers (25\%) (figure 1)

Abstract THU0655 - Table 1. Identified health care themes from focusgroup interviews

\section{Themes}

Multidisciplinary collaboration

Education of caregivers

Patient information

Role of the patient

Shared care; regional and university hospitals

Information exchange among caregivers

Organization of health care services

Non-pharmacological support

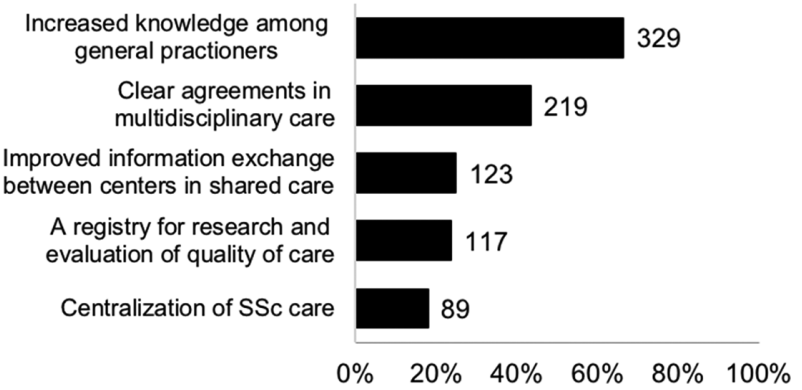

Abstract THU0655 - Figure 1 Top. five prioritised points for improvement

Conclusions: SSc patients mainly prefer more attention to symptoms during doctor's visits and wish for improved collaboration and information exchange among health care providers. This knowledge will guide the nation-wide initiative to optimise health care for patients with SSc in The Netherlands.

Disclosure of Interest: None declared

DOI: 10.1136/annrheumdis-2018-eular.3557

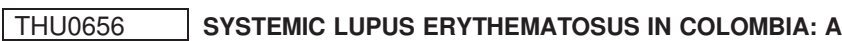 BIBLIOMETRIC ANALYSIS}

\section{J.E. Barahona-Correa. Pontificia Universidad Javeriana, Bogota, Colombia}

Background: Systemic lupus erythematosus (SLE) is a chronic autoimmune disease with a high burden of disease on individuals and healthcare systems. ${ }^{1}$
Bibliometric analyses assess scientific literature on a given topic, and allow the identification of novel research trends, based on statistical data of scientific literature and their indicators. ${ }^{2,3}$ In Colombia, few efforts have addressed at Rheumatology or Autoimmunity.

Objectives: To perform a bibliometric study on the scientific production on SLE in Colombia that describes its distribution, development trends, national and international collaboration trends, and its impact on the scientific community.

Methods: A descriptive bibliometric study was performed using three databases (Web of Science, SCOPUS and Scielo). Annual national research output, number of articles, city and institution of origin, national and international collaboration, scientific journals, publication language, and citations number were assessed. VOS viewer was used to illustrate collaboration networks.

Results: SCOPUS disclosed 307 articles, Web of Science 270, and Scielo 90 The highest number of citations per item (19.8) and the maximum national $\mathrm{H}$ index ${ }^{41}$ were found in SCOPUS. More than $80 \%$ of articles, regardless of the database, were published during the last 10 years. 'Universidad del Rosario' and 'Universidad de Antioquia' showed the highest research output. Bogotá and Antioquia, followed by Valle del Cauca, presented the highest number of articles. An important number of national and international collaborations were observed which differed in each database.

\begin{tabular}{|c|c|c|c|}
\hline \multicolumn{4}{|c|}{ Production per institution in WoS, Scielo and SCOPUS } \\
\hline Item & WoS & SCOPUS & Scielo \\
\hline Number of articles & 270 & 307 & 90 \\
\hline $\begin{array}{l}\text { Number of } \\
\text { registries }\end{array}$ & 376 & 469 & 150 \\
\hline $\begin{array}{l}\text { Articles in the last } \\
10 \text { years (\%) }\end{array}$ & 86 & 87 & 91 \\
\hline $\begin{array}{l}\text { Mean historic } \\
\text { number of } \\
\text { publications (SD) }\end{array}$ & $5.9(9.7)$ & $6.7(11)$ & $1.9(3.4)$ \\
\hline $\begin{array}{l}\text { Annual mean } \\
\text { number of } \\
\text { publications in the } \\
\text { last } 10 \text { years (SD) }\end{array}$ & $21.2(7.5)$ & $24.2(9.6)$ & $7.4(2.5)$ \\
\hline Original articles (\%) & 62 & 73 & 74 \\
\hline $\begin{array}{l}\text { National } \mathrm{H} \text { index for } \\
\text { the last } 10 \text { years }\end{array}$ & 32 & 41 & 3 \\
\hline $\begin{array}{l}\text { Total number of } \\
\text { cites }\end{array}$ & 5260 & 6093 & 39 \\
\hline $\begin{array}{l}\text { Total number of } \\
\text { cites adjusted by } \\
\text { auto-citation }\end{array}$ & 4953 & 4987 & 24 \\
\hline Mean cites per & 19.5 & 19.8 & 0.43 \\
\hline
\end{tabular}

Mean cites per

element

Most frequent

journals

(\% of grand total)

$\begin{array}{ccc}\text { 'Annals of the } & \text { 'Revista } & \text { 'Revista Colombiana de } \\ \text { rheumatic } & \text { Colombiana de } & \text { Reumatología' (68) } \\ \text { diseases'(10) 'Arthritis } & \text { Reumatología'18 } & \text { 'Acta Médica } \\ \text { and rheumatism' } & \text { 'Lupus' } & \text { Colombiana' } \\ \text { (8) } & (7) & (7)\end{array}$

a Defined as the number of positive results in each database, which may differ due to coauthors as both sum up for both institutions.

Abbreviations: WoS Web of Science, SD Standard deviation

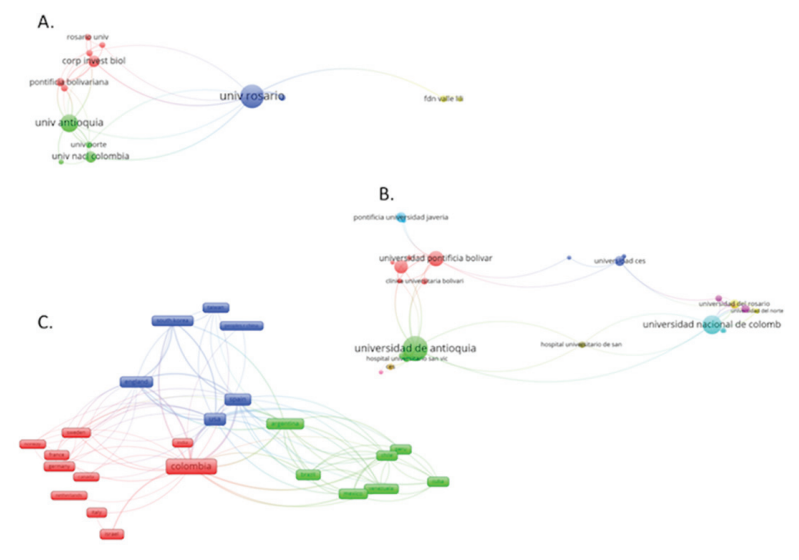

Figure. National an international collaboration networks on SLE research in Colombia. A. National (Wos) B. National (Scielo) C. International (WoS)

Conclusions: A significant growth of the research on SLE in Colombia was observed, however, its impact is far from being meaningful. Strategies aimed at strengthening the interest in Rheumatology and research in undergraduate 
students must be encouraged, particularly supporting research seedbeds and young researchers.

\section{REFERENCES:}

[1] Kaul A, Gordon C, Crow MK, Touma Z, Urowitz MB, van Vollenhoven R, et al. Systemic lupus erythematosus. Nat Rev Dis Prim 2016;2:16039.

[2] Ellegaard O, Wallin JA. The bibliometric analysis of scholarly production: How great is the impact? Scientometrics 105(3):1809-31.

[3] Li BZ, Pan HF, Ye DQ. A bibliometric study of literature on SLE research in PubMed (2002-2011). Lupus 2013;22(8):772-7.

Disclosure of Interest: None declared

DOI: 10.1136/annrheumdis-2018-eular.3497

\section{THU0657 EFFECTS OF ADALIMUMAB INITIATION ON CORTICOSTEROID UTILISATION AND MEDICAL COSTS AMONG PATIENTS WITH RHEUMATOID ARTHRITIS}

Y. Qiao ${ }^{1}$, K.L. Winthrop ${ }^{2}$, J. Griffith ${ }^{3}$, C.M. Kaplan ${ }^{1}$, C.A. Spivey ${ }^{1}$, A. Postlethwaite ${ }^{1}$, J. Wang ${ }^{1} .{ }^{1}$ University Of Tennessee Health Science Center, Memphis; ${ }^{2}$ Oregon Health Sciences University, Portland; ${ }^{3}$ AbbVie, North Chicago, USA

Background: Treatment guidelines recommend low dose corticosteroids (steroids) as a short-term ( $<3$ months) therapy among rheumatoid arthritis (RA) patients to 'bridge' patients until benefits of disease modifying anti-rheumatic drugs (DMARDs) are observed. ${ }^{1}$ However, for many patients it may be difficult to wean/eliminate steroids once they are initiated. Initiation of more effective therapies such as biologics may help promote reduction in steroid use.

Objectives: This study examined the impact of initiating adalimumab (ADA) on steroid utilisation and medical costs among patients with RA.

Methods: A retrospective analysis was conducted among adult RA patients initiating ADA as the initial biologic in the MarketScan Database (2012-2016). Study outcomes included whether oral/injectable steroids were used, daily dose, dosage categories ( $<5$ and $\geq 5 \mathrm{mg} /$ day), number of steroid injections, and medical costs. Outcomes were compared 6 months pre- and post ADA initiation using Chisquare tests for categorical variables and paired t-tests and Wilcoxon rank sum tests for continuous variables. Because various types of variables were used for study outcomes, mixed effects logistic, classical linear, multinomial logistic models, and linear model with a log link and gamma distribution were used to adjust for patient demographic and health characteristics such as age, gender, health plan type, census region, and Charlson Comorbidity Index.

Results: The study sample included 6,214 ADA initiators. As compared to the 6 months prior to ADA initiation, there was a reduction in proportions of patients using oral steroids (from $72 \%$ to $59.5 \%$ ) and injectable steroids (from $34.9 \%$ to $26.9 \%$ ), average daily dose of oral steroids (from $3.3 \mathrm{mg} /$ day to $2.5 \mathrm{mg} / \mathrm{day}$ ), patients with dose $\geq 5 \mathrm{mg} /$ day (from $22.3 \%$ to $15.1 \%$ ), number of steroid injections (from 0.63 to 0.47 ), and medical costs (from $\$ 5,233.5$ to $\$ 4,807.9$ ) ( $p<0.01$ for all comparisons). Multivariate analysis produced similar patterns. In the 6 months post-ADA initiation, patients were less likely to use oral steroids (Odds Ratio (OR): 0.40; 95\% Confidence Interval (Cl): $0.36-0.45$ ) or steroid injections (OR: 0.59; $95 \% \mathrm{Cl}: 0.54-0.65)$. Coefficient estimate for daily dose reduction was -0.87 (95\% Cl: $-1.00-0.74)$. Post-ADA relative risk ratios for dosage categories $<5$ $\mathrm{mg} /$ day and $\geq 5 \mathrm{mg} /$ day compared to zero were $0.48(95 \% \mathrm{Cl}: 0.43-0.53)$ and 0.36 (95\% Cl: 0.32-0.41), respectively. Post-ADA incidence rate ratio for number of steroid injections was $0.72(95 \% \mathrm{Cl}: 0.69-0.76)$. Ratio estimate for medical costs was $0.84(95 \% \mathrm{Cl}: 0.79-0.89)$. All multivariate results reported were significant $(\mathrm{p}<0.01)$.

Conclusions: Among patients with RA, following ADA initiation, there is a reduction in steroid utilisation and its dose, and patients' medical costs. Prospective studies should be conducted to confirm this relationship in the future.

\section{REFERENCE:}

[1] Singh JA, et al. doi:10.1002/acr.22783

Acknowledgements: Financial support for the study was provided by AbbVie. AbbVie participated in the interpretation of data, review, and approval of the abstract.

Disclosure of Interest: Y. Qiao Grant/research support from: AbbVie, K. Winthrop Grant/research support from: AbbVie, Consultant for: AbbVie, J. Griffith Shareholder of: AbbVie, Employee of: AbbVie, C. Kaplan Grant/research support from: AbbVie, C. Spivey Grant/research support from: AbbVie, A. Postlethwaite Grant/research support from: AbbVie, J. Wang Grant/research support from: AbbVie

DOI: 10.1136/annrheumdis-2018-eular.1436

\section{THU0658}

RECOMMENDATIONS FOR THE ASSESSMENT AND OPTIMISATION OF ADHERENCE TO DISEASEMODIFYING DRUGS IN CHRONIC INFLAMMATORY RHEUMATIC DISEASES: A PROCESS BASED ON LITERATURE REVIEWS AND CONSENSUS

L. Gossec ${ }^{1}$, A. Molto ${ }^{1}$, X. Romand ${ }^{1}$, D. Puyraimond-Zemmour ${ }^{1}$, M. Lavielle $^{2}$ C. Beauvais ${ }^{2}$, E. Senbel' ${ }^{2}$, R.-M. Flipo ${ }^{2}$, S. Pouplin', C. Richez ${ }^{2}$, A. Saraux ${ }^{2}$, L. Gutermann ${ }^{2}$, P. Gaudin ${ }^{2}$, D. Wendling ${ }^{2}$, M. Dougados ${ }^{2} .{ }^{1}$ Rencontres d'Experts 2017 Working Group, Paris; ${ }^{2}$ Rencontres d'Experts 2017 Working Group, Paris, France

Background: In chronic inflammatory rheumatic diseases including rheumatoid arthritis (RA), spondyloarthritis (SpA), psoriatic arthritis (PsA) and connective tissue diseases (CTD), adherence to disease-modifying drugs is only moderate over the long term and non-adherence may lead to complications, unnecessary treatment switches and heightened costs.

Objectives: To develop recommendations to facilitate in daily practice, the measurement of non-adherence, the individualised assessment of risk of non-adherence and the management of non-adherence with the objective to optimise adherence to treatments in patients with chronic inflammatory rheumatic diseases.

Methods: The project scope was limited to chronic inflammatory rheumatic diseases (i.e., RA, SpA, PsA, CTD, cristal-induced arthritis, vasculitis and autoinflammatory diseases), and to disease-modifying drugs (i.e., mainly conventional DMARDs, biologics and targeted synthetic DMARDs). The process comprised (a) systematic literature reviews of data from 3 key databases and several websites, of methods (including questionnaires) to measure non-adherence, risk factors for non-adherence and management options for non-adherence with their reported efficacy. (b) a consensus of 104 rheumatologist and nurse experts during a 2 day face-to-face meeting. (c) Final recommendations were anonymously evaluated by the participants for agreement and ease of applicability (1-5 were 5 is highest).

Results: (a) After screening 1131 publications and 194 other documents, 231 relevant papers were analysed. (b) The consensus process led to 5 overarching principles and 10 recommendations regarding adherence. In summary, adherence is important, imperfect, and multi-factorial. Patient-physician interactions play an important role, as do patient beliefs. Adherence should be assessed at each outpatient visit, at least using an open question. Questionnaires and hydroxychloroquine blood level assessments may also be useful. People who are younger, worried of side effects, do not see the necessity of the treatment, and are in psychological distress are more prone to non-adherence. Patient information and education, and patient/physician shared decision, are key to optimise adherence. Other techniques such as formalised education sessions, motivational interviewing and cognitive behavioural therapy may be useful. All health professionals can get involved and e-health may be a support. (c) The agreement with the recommendations was high (range of means, 3.88-4.47) but ease of applicability was lower (2.69-4.38).

Conclusions: Using an evidence-based approach followed by expert consensus, this initiative should improve the assessment and optimisation of adherence in chronic inflammatory rheumatic disorders. Next steps include dissemination and implementation.

Acknowledgements: AbbVie France funded this initiative but played no role in the recommendations.

Disclosure of Interest: None declared

DOI: 10.1136/annrheumdis-2018-eular.2340

\section{THU0659 EURORHEUMAVISION: ARE THE LARGEST EUROPEAN RHEUMATOLOGY SOCIETIES THE ONES WITH THE MOST ORAL COMMUNICATIONS?}

M. Paulino Huertas. Rheumatology, Hospital General De Ciudad Real, Ciudad Real, Spain

Background: Between June 14 ant 17,2017, coinciding with the 70th anniversary of its foundation, the annual EULAR congress took place in Madrid. With 14.000 participants from 130 countries, 4845 accepted abstracts, 2300 posters and more than 800 oral communications, it became a record congress in the history of European rheumatology.

Now, EULAR is formed, among others, by 45 national rheumatology societies Are the various countries proportionally represented at a scientific level? Those with the greatest number of rheumatologists have a greater weiight in communications to the congress?

Objectives: To assess the scientific weight of the different European rheumatological societies in the EULAR congress

Secondary objective: To analyse the characteristics of these societies in terms of the number of rheumatologists, specialists for 100,0000 inhabitants and percentage with the total number of doctors 